\title{
Fitoplancton del lago Zempoala
}

\author{
Judith García-Rodríguez ${ }^{1}$ y Rosaluz Tavera ${ }^{2}$ \\ ${ }^{1}$ Laboratorio de Hidrobiología, Centro de Investigaciones Biológicas. \\ Universidad Autónoma del Estado de Morelos. ${ }^{2}$ Laboratorio de Ficología, Departamento \\ de Biología, Facultad de Ciencias, Universidad Nacional Autónoma de México. \\ e-mail: rts@hp.fciencias.unam.mx
}

\begin{abstract}
Resumen: Se presenta la composición del fitoplancton del lago Zempoala que fue estudiado de abril de 1996 a julio de 1997. La caracterización taxonómica, ecológica y de distribución geográfica de las especies pone de manifiesto que el fitoplancton es más común en zonas templadas que tropicales y que las variaciones estacionales tales como discontinuidades en su distribución en la columna (parches), densidad y dominancia de especies, corresponden con las fluctuaciones fisicoquímicas anuales periódicas, (alogénicas) y con la interacción con la comunidad del zooplancton (autogénicas).

Palabras clave: Fitoplancton, lagos, parches de distribución, trópicos, Zempoala, México.

Abstract: The phytoplankton of lake Zempoala was studied from April 1996 to July 1997. The taxonomy, ecology and geographical distribution of species show that their presence is more common in temperate than tropical areas. Seasonal variations in patching, density and dominant species of the phytoplankton are corresponding with the annual physical and chemical periodical changes (allogenics), and with the zooplancton community interactions (autogenics).
\end{abstract}

Key words: Phytoplankton, lakes, patching, tropics, Zempoala, Mexico.

E estudio de este lago forma parte del proyecto "Limnología de los lagos del Parque Nacional de Lagunas de Zempoala”, de la Universidad Autónoma del Estado de Morelos. El estudio de comunidades lénticas es importante para nuestro país porque contamos con pocos recursos acuáticos continentales de este tipo. El conocimiento estacional de la biota en relación con las condiciones climáticas puede hacer posible el manejo adecuado de cuencas, si permite un cierto grado de predicción sobre los cambios que puedan ocurrir y sobre las posibles causas y sus consecuencias. El estudio que presentamos pone de manifiesto la importancia de integrar un estudio taxonómico (la caracterización biológica de las especies del fitoplancton) con un análisis de las características ecológicas (físicas, químicas y de otras comunidades) que enmarcan la presencia de esas especies. Es interesante que la influencia que tiene la ubicación geográfica (latitudinal) del lago Zempoala, sobre la composición del fitoplancton, se ve modulada por otros factores ambientales como la temperatura, la altitud o el tipo de suelo, los que posiblemente influyen además en la dinámica de la comunidad biótica en conjunto.

\section{Área de estudio}

Junto con otros 7 lagos, el Zempoala forma parte del Parque Nacional Lagunas de Zempoala, (Bonilla, 1992) situado a $65 \mathrm{~km}$ al sur de la ciudad de México y a $38 \mathrm{~km}$ al noroeste de la ciudad de Cuernavaca, Morelos (figura 1). La ubicación del lago es $19^{\circ} 03^{\prime}$ $00^{\prime \prime}$ y $99^{\circ} 18^{\prime} 42^{\prime \prime}$.

Geología y edafología. El Parque se encuentra dentro de la Provincia Fisiográfica del Eje Volcánico Transversal, originada durante la Revolución Laramídica, cuando se conformó la Sierra de Zempoala. La cuenca comprende rocas de origen volcánico de composición andesítica, dacítica y riodacítica. Además presenta brechas volcánicas, derrames lávicos y capas tobáceas, que forman parte de los depósitos del Mioceno y la mayor parte del Plioceno (Aceves-Quezada, 1990). 
Estas rocas contienen $10 \%$ de materia orgánica y están a una profundidad de 10 a $50 \mathrm{~cm}$ en la fase lítica. Los suelos dominantes de la región son andosoles de tipo húmico, derivados de material volcánico reciente, con alta capacidad de retener agua, de erosionarse y de fijar fósforo (López-García, 1990).

Vegetación y clima. Los tipos de vegetación presentes en este Parque son encinar, pinar y bosque de oyameles (Miranda y Hernández, 1963), propios de la Provincia de las Serranías Meridionales. El clima que predomina es el tipo más húmedo de los templadosubhúmedo con lluvias en verano $\mathrm{C}\left(\mathrm{w}_{\mathrm{g}}\right)$ (w) , con un cociente $\mathrm{P} / \mathrm{T}$ mayor a 55 y un porcentaje de lluvia invernal muy escaso. La temperatura media anual oscila entre 12 y $18^{\circ} \mathrm{C}$ y la del mes más frío entre -3 y $18^{\circ} \mathrm{C}$ (García, 1990).

El lago Zempoala está situado a una altura de 2800 msnm y presenta agua durante todo el año. Se trata de una cuenca endorreica formada muy posiblemente por represación, con drenaje de tipo torrencial que sólo lleva agua en temporada de lluvias. Tiene una superficie de $105.64 \mathrm{~m}^{2}$ en el estiaje y de $123.40 \mathrm{~m}^{2}$ en la época de lluvias. El ancho máximo es de 403.5 metros (ancho promedio de $207.9 \mathrm{~m}$ ); el largo máximo en dirección NNE-SSO es de $508 \mathrm{~m}$. Aunque no existen datos sobre la batimetría, dado el origen del lago es probable que el fondo tenga un perfil irregular, así que podríamos considerar un volumen aproximado de $528066 \mathrm{~m}^{3}$, pues registramos una profundidad máxima de 5 metros.

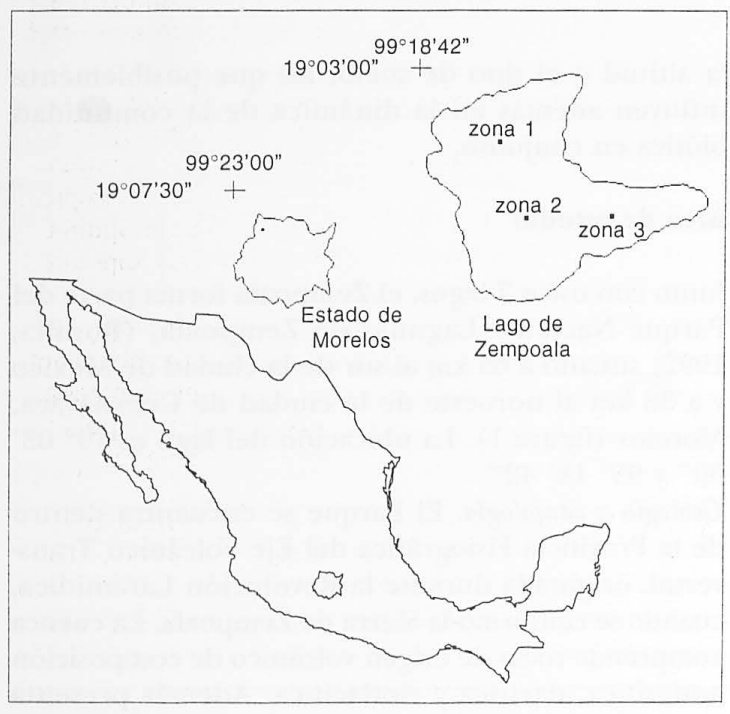

Figura 1. Ubicación del lago y una ampliación mostrando las zonas recolectadas.

\section{Métodos}

El estudio del lago comprendió recolectas realizadas mensualmente de abril de 1996 a julio de 1997. Se tomaron muestras de la columna (superficie, 1, 2.5 y 5 metros de profundidad) en tres zonas del lago (figura 1). Se obtuvo la transparencia por profundidad de Secchi y la concentración de clorofila por el método de Boyd (Vollenweider, 1974) con corrección para feofitinas. Para los muestreos se utilizó una botella van Dorn de 31 y los cálculos de densidad se obtuvieron a partir de submuestras de $250 \mathrm{ml}$ preservadas con lugol, de acuerdo con el método de Kollkwitz-Utermöhl con un microscopio invertido Wild M-40. Para designar a una especie como abundante se consideró un mínimo de 400 individuos por litro presentes en la columna, en cualquier profundidad. Para la determinación de las especies se utilizaron muestreos de red ( $10 \mu \mathrm{m}$ abertura de malla) que fueron preservados con formol al $2 \%$. Las referencias de herbario se depositaron en el Herbario de la Facultad de Ciencias de la UNAM (FCME).

Se determinó la concentración de algunos nutrimentos inorgánicos disueltos en los meses de abril, mayo, junio, julio, septiembre, octubre y noviembre de 1996, con un litro de agua filtrada, obtenida del primer metro de profundidad. Para esta determinación se utilizaron los métodos propuestos por la USEPA (The United States Environmental Protection Agency), aprobados para reportes científicos (APHA, 1992), utilizando un espectrofotómetro Hach, modelo DR 2 000. Los valores determinados se presentan en los resultados como intervalos máximo y mínimo.

Se documentó la distribución geográfica de las especies para explicar su presencia en Zempoala a pesar de tener una distribución templada.

\section{Resultados}

Caracterización taxonómica de las especies. La columna de caracterización geográfica del cuadro 1 resume nuestra consideración sobre la distribución de las especies. Más de la mitad de ellas son cosmopolitas y no dan un perfil definido del lago y las 9 restantes, 5 tienen una distribución templada; el único registro para un área tropical sería el presente trabajo, pero dadas las características climáticas del lago Zempoala no consideramos conveniente asignar una distribución tropical. Las otras 4 especies han sido registradas previamente para México, pero en tanto es la única fuente hemos considerado un carácter cosmopolita dudoso. En este sentido, es notable que las fuentes bibliográficas utilizadas son trabajos florísticos de regiones templadas, exceptuando las citas de Comas (1996) y Novelo (1998). 
La clasificación sistemática utilizada es particular para las Clases y Ordenes algales. Las Chlorophyta se basan en Komárek y Fott (1983) para Chlorococcales; en Prescott (1962) y Prescott et al. $(1981,1982)$ para Volvocales y Desmidiales, así como para Heterokontophyceae; en Huber- Pestalozzi (1955) para Euglenophyceae; en Popovsky y Pfeister (1990) para Dinophyceae; en Starmach (1985) para Chrysophyceae; en Gardner (1927) y Geitler (1932) para Cyanophyceae; en Patrick y Reimer (1966) y Kramer y Lange-Bertalot (1991a, 1991b, 1998) para Bacillariophyceae.
Clase Chlorophyceae, Orden Chlorellales, Familia Selenastraceae

Gregiochloris lacustris (Chod.) Marvan, Komárek et Comas, figura $2 \mathrm{a}, \mathrm{b}$.

Colonias de 4 células dispuestas irregularmente, envueltas en un mucilago. Las células son fusiformes atenuándose hasta el ápice que es agudo. Presentan un cloroplasto parietal con un pirenoide. Dimensiones: células de 15.7 × $3.4 \mu \mathrm{m}$. Colonia de 50.7 × 23.2 $\mu \mathrm{m}$.

Cuadro 1. Caracterización ecológica y geográfica de las especies del fitoplancton del lago Zempoala.

\begin{tabular}{|c|c|c|c|c|c|c|}
\hline \multirow[b]{2}{*}{ ESPECIE } & \multicolumn{2}{|c|}{$\begin{array}{l}\text { CARACTERIZACIÓN } \\
\text { ECOLÓGICA }\end{array}$} & \multicolumn{3}{|c|}{$\begin{array}{l}\text { REGISTROS MUNDIALES PARA } \\
\text { LA ESPECIE }\end{array}$} & \multirow[t]{2}{*}{$\begin{array}{l}\text { CARACTERIZACIÓN } \\
\text { GEOGRÁFICA }\end{array}$} \\
\hline & AMBIENTE & F. DE V. & TEMPLADA & TROPICAL & MÉXICO & \\
\hline Gregiochloris lacustris & Le & planctónica & + & & ++ & cosmopolita? \\
\hline Monoraphidium griffithii & $\mathrm{Lo}+\mathrm{Le}$ & planctónica? & + & & +++ & templada \\
\hline Oocystis marsonii & Le & planctónica & + & + & t++ & cosmopolita \\
\hline $\begin{array}{l}\text { Scenedesmus opoliensis } \\
\text { var. monoensis }\end{array}$ & Le & planctónica & + & + & ++ & cosmopolita \\
\hline Pandorina smithii & Le & planctónica & + & + & +++ & cosmopolita \\
\hline Arthrodesmus convergens & Le & planctónica & + & & +++ & templada \\
\hline $\begin{array}{l}\text { Staurastrum sebaldii } \\
\text { var. ornatun f. planctonica }\end{array}$ & & & + & & +++ & templada \\
\hline Cosmarium subtumidum & Le & planct. perifítica & + & + & +++ & cosmopolita \\
\hline Trachelomonas stokesiana & Le & planctónica & + & & +++ & templada \\
\hline Trachelomonas hispida & Lo + Le & planct. perifítica & + & & ++ & cosmopolita? \\
\hline Ceratium hirundinella & Le & planctónica & + & & ++ & cosmopolita? \\
\hline $\begin{array}{l}\text { Dinobryon sociale } \\
\text { var. americanum }\end{array}$ & Le & plánct. epífita & + & & ++ & cosmopolita? \\
\hline Tribonema bombycinum & Lo + Le & planctónica & + & + & ++ & cosmpolita \\
\hline Microcystis protocystis & Le & planctónica & + & + & ++ & cosmopolita \\
\hline Asterionella formosa & Le & planct. béntica & + & + & ++ & $\begin{array}{l}\text { cosmopolita, } \\
\text { rara en trópicos }\end{array}$ \\
\hline Fragilaria crotonensis & Le & planctónica & + & + & ++ & cosmopolita \\
\hline Synedra ulna & Lo + Le & $\begin{array}{l}\text { desde edáfica } \\
\text { a planctónica }\end{array}$ & + & + & ++ & cosmopolita \\
\hline Gomphonema acuminatum & Le & $\begin{array}{l}\text { planct. bénctica, } \\
\text { epífita, perifítica }\end{array}$ & + & + & ++ & $\begin{array}{l}\text { cosmopolita, } \\
\text { más abundante } \\
\text { en templadas }\end{array}$ \\
\hline Gomphonema affine & Le & litoral, edáfica & + & + & ++ & cosmopolita \\
\hline $\begin{array}{l}\text { Frustulia rhomboides } \\
\text { var. capitata }\end{array}$ & Le & planctónica & + & & +++ & templada \\
\hline Nitzschia frustulum & Lo + Le & - & + & + & ++ & cosmopolita \\
\hline Epithemia turgida & Lo + Le & $\begin{array}{l}\text { litoral, epífita } \\
\text { o perifítica }\end{array}$ & + & + & ++ & cosmopolita \\
\hline Achnanthes minutissima & Lo + Le & $\begin{array}{l}\text { planct. bénctica, } \\
\text { epífita, perifítica }\end{array}$ & + & + & ++ & cosmopolita \\
\hline
\end{tabular}

Le = Ambiente léntico: Lago, presa, charco o estanque.

Lo = Ambiente lótico: Río, arroyo, canal o manantial.

$++=$ Registrada previamente en México.

$+++=$ Registrada actualmente en el lago Zempoala. 

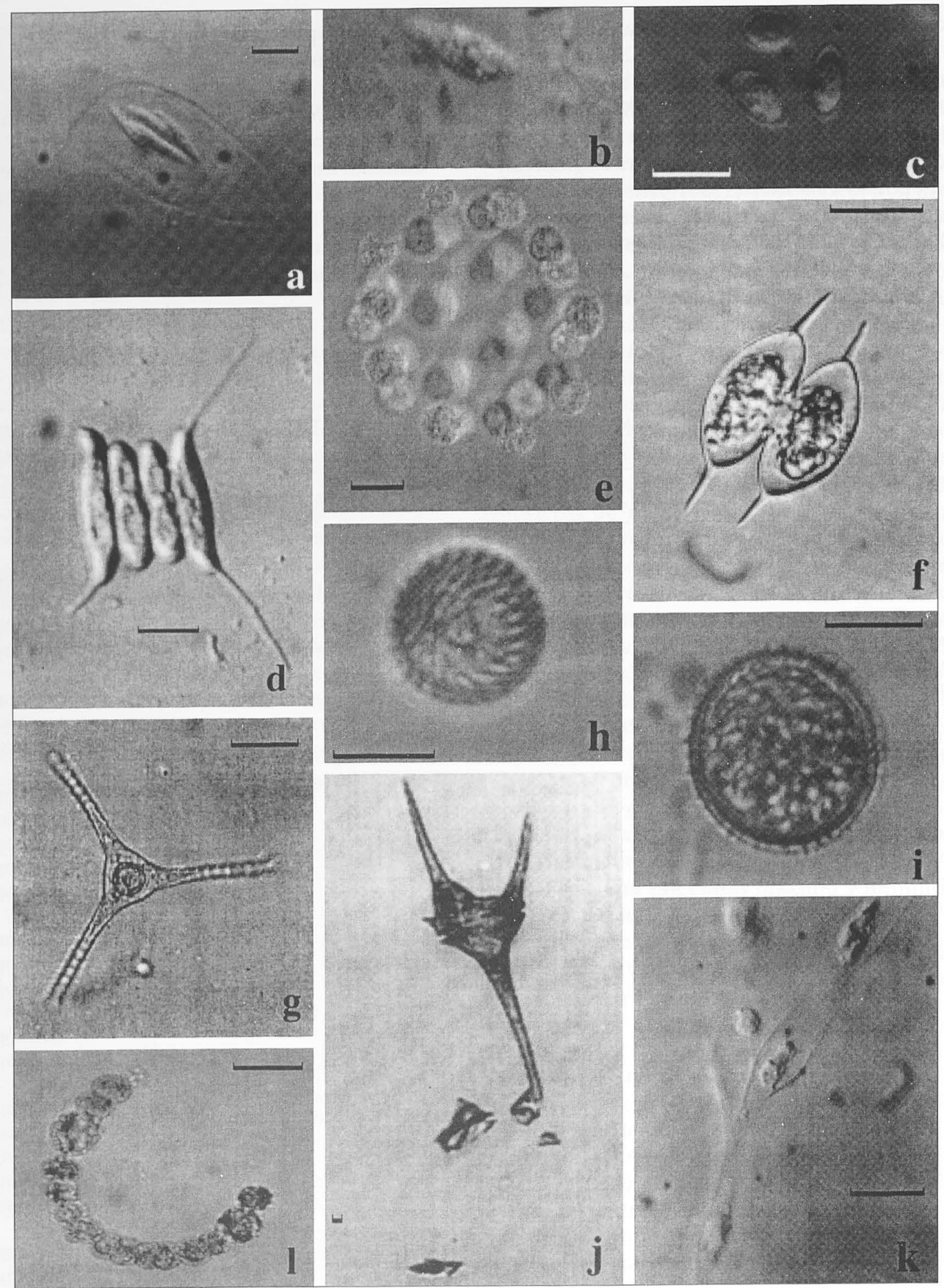

Figura 2. $a-b$ ] Gregiochloris lacustris Marvan, Komárek et Comas; $c$ ] Oocystis marssonii Lemmermann; d] Scenedesmus opoliensis Richter var. mononensis Choda; e]. Pandorina smithii Chodat; f] Arthrodesmus convergens Ehrenberg ex Ralfs; g] Staurastrum sebaldi var. ornatum f. planctonica (Lütkerm) Teilim.; h] Thrachelomonas stokesiana Palmer; i] Trachelomonas hispida Perty Stein emend. Deflandre; j] Ceratium hirundinella (O. F. Müller) Dujardin non Schrank; $k$ ] Dinobryon sociale var. americanum (Brunnthaler) Bachmann; l] Anabaena sp. Bory. La barra equivale a $10 \mu m$. 
Distribución en el mundo: en lagos limpios en Estados Unidos, Dinamarca y Suiza (Komárek y Fott, 1983). No hay registros en México.

Poco abundante y esporádica en las tres zonas y presentó su mayor abundancia en la zona 2 ( figura 1), en junio de 1997. Registrada en este lago en toda la columna de agua.

Monoraphidium griffithii (Berk.) Komárková-Legnerová. Célula fusiforme, más de 12 veces más larga que ancha, hacia la parte terminal de la célula ésta se va haciendo aguda. Pared celular lisa. Dimensiones: 42.2 x $1.9 \mu \mathrm{m}$.

Distribución en el mundo: cosmopolita (Komárek y Fott, 1983; Novelo, 1998).

Distribución en México: México, D.F.

Presente esporádicamente y poco abundante en las tres zonas y presentó su mayor abundancia en la zona 1, el mes de febrero de 1997. Registrada en este lago en toda la columna de agua.

\section{Familia Oocystaceae, Subfamilia Oocystoideae.}

Oocystis marssonii Lemmermann, figura 2 c.

Células fusiforme-ovales, a veces ensanchadas en la parte media; polos redondeados a levemente obtusos; a veces solitarias o en colonias pequeñas de 24 células. Uno o dos cloroplastos parietales, cada uno con un pirenoide. Dimensiones: 9.6 x $5.7 \mu \mathrm{m}$. Komárek y Fott (1983) consideran que las características más importantes en el género al que pertenece esta especie, son la pared lisa y la permanencia de las autósporas dentro de la pared celular materna, durante la reproducción. Son cautelosos con respecto a la presencia de pirenoides, señalando que en algunas especies no se han observado. Comas (1996) señala que los caracteres diacríticos de este género no están bien definidos pero que la presencia de pirenoides podría considerarse como variación interespecífica y no genérica, como señala Hindák (1988), que propone la inclusión de las especies con pirenoide en el género Oocystella Lemmermann, e incluso describe varias especies y hace algunas combinaciones nuevas. En el presente artículo, nosotros respetamos el género Oocystis con pirenoides presentes para la especie registrada en Zempoala.

Distribución en el mundo: cosmopolita (Komárek y Fott, 1983; Novelo, 1998).

No hay registros en México.

Esta especie presentó su mayor abundancia en la zona 2, el mes de junio de 1997, en los otros meses siempre poco abundante y esporádica en las tres zonas. Registrada en este lago en toda la columna de agua.
Familia Scenedesmaceae, Subfamilia Scenedesmoideae. Scenedesmus opoliensis Richter var. mononensis Chodat, figura $2 \mathrm{~d}$.

Cenobios con células unidas paralelamente en más de $1 / 3$ de su longitud. Células con los lados redondeados, extremos de las células ligeramente alargados y los polos más o menos truncados. Las espinas se asientan excéntricamente sobre el polo. Dimensiones: 21 x $5.5 \mu \mathrm{m}$.

Distribución en el mundo: cosmopolita (Novelo, 1998)

Distribución en México: registrada muy abundante en Xochimilco, D.F. con poblaciones con alta variabilidad morfológica (Comas, A., Novelo, E. y R. Tavera, datos no publ.).

Esta especie presentó su mayor abundancia en la zona 3, el mes de mayo de 1997. Los demás meses fue esporádica y poco abundante en las tres zonas. Registrada en este lago en toda la columna de agua. Frecuentemente los ejemplares mostraron espinas incompletas y con sólo 2 o 3 células por cenobio.

Clase Chlamydophyceae, Orden Volvocales, Familia Volvocaceae.

Pandorina smithii Chodat, figura 2 e.

Colonia esférica, la mayoría de los individuos con 16 células colocadas periféricamente formando un espacio vacío en la parte central. Células esféricas. Cloroplastos en forma de copa, con un pirenoide. Dimensiones de células $9.9 \mu \mathrm{m}$ de diámetro y de la colonia, $98.4 \mu \mathrm{m}$.

Distribución en el mundo: Suiza y República Checa (Prescott, 1962).

No hay registros en México.

Esta especie presentó la mayor abundancia en la zona 2, junio de 1997. Los demás meses fue esporádica y poco abundante en las tres zonas. Registrada en este lago en toda la columna de agua.

\section{Orden Desmidiales, Familia Mesotaeniaceae}

\section{Arthrodesmus convergens Ralfs, figura $2 \mathrm{f}$.}

Células $1 /{ }_{5} \mathrm{a} 1 / \mathrm{z}_{3} \tan$ largas como anchas, con constricción media profunda, el sinus muy profundo, angular y agudo, con un extremo redondeado, hemicélulas transversalmente elípticas, los márgenes basales transversalmente subelípticos y ligeramente convexos, con ángulos atenuados, agudos y poco proyectados hacia abajo. Presenta espinas curvadas, el apéndice relativamente ancho y convexo, el contorno del apéndice y las espinas forman un arco; la pared celular es lisa. Las hemicélulas son semicirculares en vista lateral, en vista frontal son estrechamente 
elípticas, con una espina larga en los polos. Dimensiones: ancho de la hemicélula con espinas $58.5 \mu \mathrm{m}$ y $\sin$ espinas $39.5 \mu \mathrm{m}$, largo $35.0 \mu \mathrm{m}$.

Distribución en el mundo: Estados Unidos: Carolina, Canadá (Prescott et al., 1982), Suecia (Novelo, 1998).

No hay registros en México.

Fue una especie esporádica y poco abundante y presentó mayor abundancia en la zona 2, el mes de mayo de 1996; sólo se registró en la superficie de las zonas 1 y 2 .

Staurastrum sebaldi (Rensch) var. ornatum f. planctonica (Lütkerm) Teilim, figura $2 \mathrm{~g}$.

La hemicélula es triangular, con el margen ligeramente cóncavo entre los brazos; presenta un par de pequeñas pero conspicuas verrugas en el margen ventral de la base de los brazos; la base de la hemicélula está engrosada y presenta gránulos cientro de cada brazo. Dimensiones de la hemicélula 31 de largo $\mathrm{x} 65.5 \mu \mathrm{m}$ de ancho (con brazos); ancho del istmo $9.5 \mu \mathrm{m}$.

Distribución en el mundo: Estados Unidos, Europa, África, América Central y América del Sur (Prescott et al., 1982), Suecia (Novelo, 1998)

No hay registros en México.

Esta especie fue frecuente aunque poco abundante en las tres zonas y presentó su mayor abundancia en la zona 1, el mes de marzo de 1997. Registrada en este lago en toda la columna de agua.

Familia Desmidiaceae

Cosmarium subtumidum Nordstedt in Wittrock \& Nordstedt.

Células de 1 a 1.2 veces más largas que anchas; constricción media profunda, sinus cerrado, hemicélula semicircular, generalmente con el ángulo basal y apical redondeado, ápices truncados. Hemicélulas circulares en vista lateral, en vista apical generalmente elípticas, ligeramente engrosadas en la región media. Cloroplasto con un pirenoide. Dimensiones de la célula: 23.6 x $20.4 \mu \mathrm{m}$. Las poblaciones presentes en el lago Zempoala coinciden con todos las caracteres descritos para esta especie, aunque de menor ancho celular que el registrado en la literatura.

Distribución en el mundo: cosmopolita, en todos los continentes y en el Ártico. (Prescott et al., 1981; Novelo, 1998).

No hay registros en México.

Esta especie fue esporádica y poco abundante en las tres zonas y presentó su mayor abundancia en la zona 2, el mes de mayo de 1997; Registrada en este lago en toda la columna de agua.
Clase Euglenophyceae, Orden Euglenales, Familia Euglenaceae.

Trachelomonas stokesiana Palmer, figura $2 \mathrm{~h}$.

Lórica esférica, fuertemente espiralada; presenta una pared fina, de color pardo y la cara superficial con estrías gruesas y anchas. En el ápice tienen un collarete chato, cónico y corto situado en la depresión apical de la célula; del collarete sale un flagelo largo. Dimensiones: $15 \mu \mathrm{m}$.

Distribución en el mundo: se distribuyen en Norte América y Europa (Hubber-Pestalozzi, 1955).

No hay registros en México.

Esta especie fue abundante en las tres zonas y más abundante en la zona 2, el mes de junio de 1996. Registrada en este lago en toda la columna de agua.

Trachelomonas hispida (Perty) Stein emend. Deflandre, figura $2 \mathrm{i}$.

Lórica elipsoidal, compacta, con espinas cortas, cónicas, muy agudas. Pared celular pardo-rojiza, finamente punteada, aunque a veces da la apariencia de estar lisa. Collarete corto o inexistente. Dimensiones: $25.2 \times 20.8 \mu \mathrm{m}$.

Distribución en el mundo: cosmopolita. Rara en el plancton de lagos (Hubber-Pestalozzi, 1955).

Distribución en México: Puebla.

Fue una especie abundante, presente durante todas las recolectas en las tres zonas. Fue más abundante en la zona 2, el mes de junio de 1996. Registrada en este lago en toda la columna de agua.

Clase Dinophyceae, Orden Peridiniales, Familia Peridinaceae.

\section{Peridinium sp.}

Células elipsoidales o esféricas. La fórmula de su placa es 4',(2a-3a),6"; $4^{\prime \prime \prime}, 2^{\prime \prime \prime " . ~ L a ~ m a y o r i ́ a ~ d e ~ l o s ~ e j e m p l a-~}$ res observados en este lago presentaron las células dañadas, en ocasiones plasmolizadas o incompletas. El escaso contenido y daño de la lórica hicieron imposible la documentación completa de la especie.

La mayor abundancia para esta especie fue registrada en el mes de febrero de 1997 y observada de manera ocasional en las tres zonas, rara vez abundante. Registrada en este lago en toda la columna de agua.

\section{Familia Ceratiaceae}

Ceratium hirundinella (O. F. Müller) Dujardin non Schrank, figura $2 \mathrm{j}$.

Células poligonales. La lórica forma una epivalva que se estrecha formando un cuerno largo, justamente arriba del cíngulo. Cíngulo transversalmente estrecho. 
Cuerpo de la hipovalva ancho y corto, divididc en 2 a 3 cuernos posteriores. Placas gruesas con espículas finas. Dimensiones: 29.7 x $20.4 \mu \mathrm{m}$. Cuernos hipovalvares de 66 y $120 \mu \mathrm{m}$; cuerno epivalvar de $15 \$ .3 \mu \mathrm{m}$.

Distribución en el mundo: cosmopolita (Novelo, 1998).

Distribución en México: México, D.F., Jalisco, Michoacán, Puebla, Veracruz.

Fue una especie esporádica de baja abundancia en las tres zonas y presentó su mayor abundancia en la zona 1, el mes de mayo de 1997. Registrada en este lago en toda la columna de agua.

Clase Chrysophyceae, Orden Ochromonadales, Familia Dinobryaceae

Dinobryon sociale (Ehr.) var. americanum (Brunnthaler) Bachmann, figura $2 \mathrm{k}$.

Células incluidas en una teca, reunidas en colonias ramificadas; la célula está unida a la teca por un pedículo muy poco visible. La pared de la teca es delgada e incolora. Dimensiones de la teca 11.3 x 5.9 $\mu \mathrm{m}$. En ocasiones se observaron algunas tecas vacías en las colonias y éstas variaron en su ramificación y en el número de células.

Distribución en el mundo: Europa (Starmach, 1985); Estados Unidos; Canadá (Novelo, 1998).

Distribución en México: México, D.F.

Esta especie presentó su mayor abundancia en la zona 3, en mayo de 1997; en el resto de las recolectas fue poco abundante. En general fue esporádica en las tres zonas. Registrada en este lago en toda la columna de agua.

Clase Xanthophyceae, Orden Tribonematales, Familia Tribonemataceae.

Tribonema bombycinum (C.A.Aq.) Derbés \& Solier:

Células con paredes delgadas, cilíndricas, ligeramente constreñidas en los septos. Dimensiones: 42 x 10 $\mu \mathrm{m}$. 4-8 pequeños cloroplastos, parietales, discoides, verde-amarillentos.

Distribución en el mundo: Estados Unidos; Suecia; Canadá (Novelo, 1998).

Distribución en México: Puebla.

Fue una especie esporádica y poco abundante en las tres zonas y presentó su mayor abundancia en la zona 2, en el mes de agosto de 1996. Registrada en este lago en toda la columna de agua.

Clase Cyanophyceae, Orden Nostocales.

Anabaena sp., figura 21.

Tricomas uniformemente anchos un poco atenua- dos hacia los ápices. Presentan un heterocito generalmente intercalar; no observamos acinetos. Los tricomas siempre semicirculares y con muy pocas células. Fue una especie esporádica y poco abundante; presentó su mayor abundancia en la zona 1, en el mes de junio de 1997. Su distribución sólo fue observada a $1 \mathrm{~m}$ de profundidad. Dimensiones: células de $5 \mu \mathrm{m}$ de diámetro; heterocitos de $6.6 \mu \mathrm{m}$ de diámetro.

Anabaena cf. portoricensis Gardner, figura 3 a.

Células esféricas, comprimidas en los polos. Usualmente las células terminales son más pequeñas que las restantes del tricoma y además anchamente cónicas. Siempre fueron observados filamentos con más de 5 células, con un heterocito. Hay una gran similitud morfológica de las poblaciones de Zempoala con las de A. portoricensis (Gardner, 1927) de Puerto Rico sin embargo, hemos preferido aplicar el epíteto con cautela porque Gardner (1927) describe las poblaciones portorricenses creciendo en canales, lo que no corresponde con exactitud con las de Zempoala (i.e. planctónicas). Dimensiones: 6 de largo x $7 \mu \mathrm{m}$ de ancho. Heterocito semiesférico $11 \mu \mathrm{m}$ de largo y 10.5 $\mu \mathrm{m}$ de ancho.

Distribución en el mundo: Puerto Rico (creciendo en canales) (Gardner, 1927; Geitler 1935).

No hay registros en México.

Fue una especie esporádica en las tres zonas, no siempre abundante; la mayor abundancia se observó en la zona 1, en el mes de octubre de 1996. Registrada en este lago en toda la columna de agua.

Orden Chroococcales, Familia Chroococcaceae.

Microcystis protocystis Crow, figura $3 \mathrm{~b}$, c.

Colonias irregulares con un mucilago confluente. Células numerosas, esféricas, de color verdeazul muy pálido; dispuestas a veces laxamente, a veces compactas. Dimensiones: células de $2.6 \times 1.6 \mu \mathrm{m}$.

Distribución en el mundo: India (Desikachary, 1959); Argentina (Novelo, 1998).

Distribución en México: Oaxaca.

Fue una especie esporádica, poco abundante en las tres zonas y presentó su mayor abundancia en la zona 1, en el mes de mayo de 1996. Registrada en este lago en toda la columna de agua.

Clase Bacillariophyceae, Orden Pennales, Familia Fragilariaceae.

Asterionella formosa Hass, figura $3 \mathrm{f}$.

Colonias con 6 células, cuando hubo numerosas células, mostraron un aspecto de ramillete. Valvas lineares con ápices capitados, con la parte final uni- 


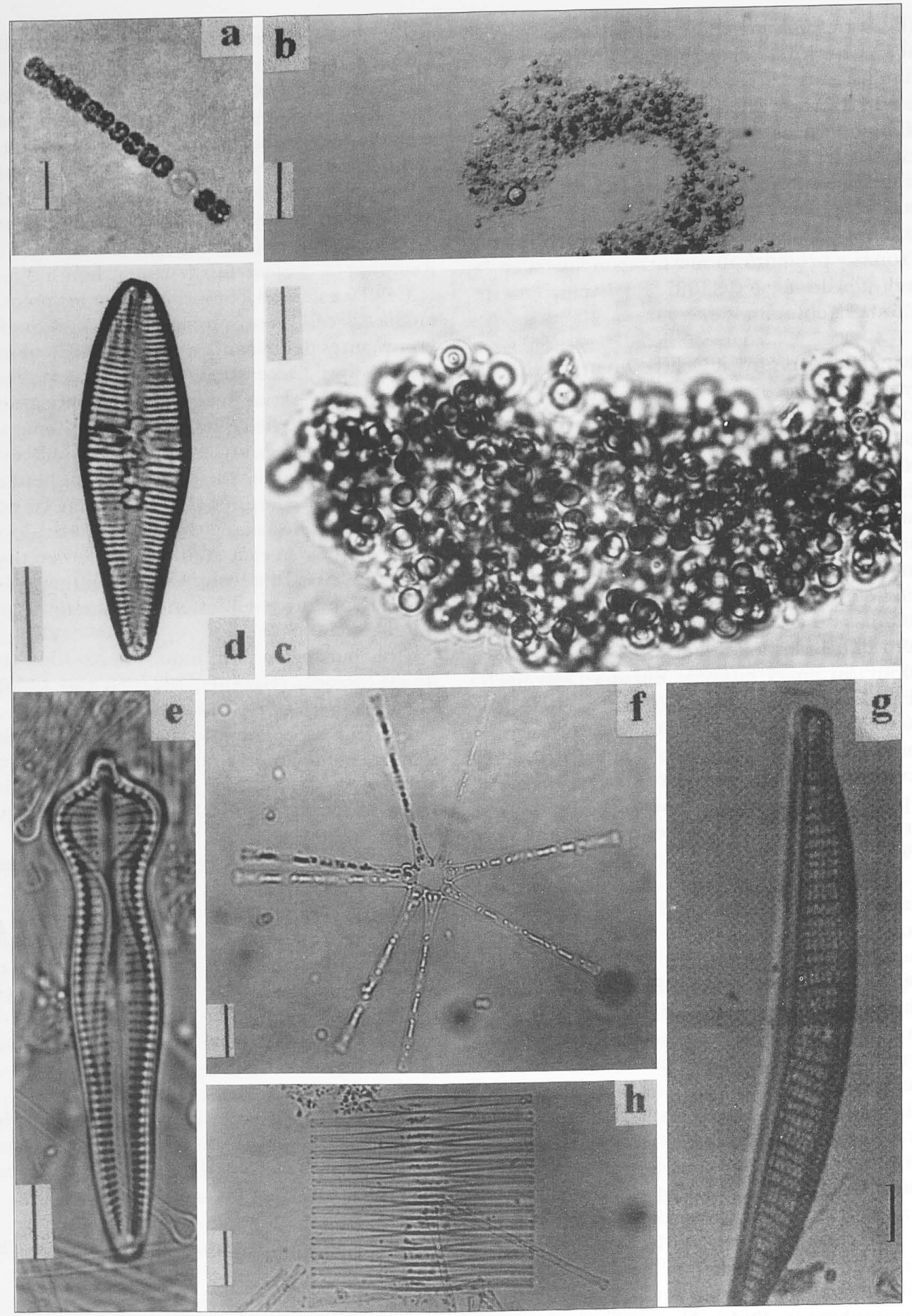

Figura 3. a] Anabaena cf. portorricensis Gardner; $b c$ c Microcystis protocystis Crow; d] Gomphonema affine Kützing; e] Gomphonema acuminatum Ehrenberg; $f$ Asterionella formosa var. formosa Hass; g] Epithemia turgida (Ehrenberg) var. granulata (Ehr.) Brun; h] Fragilaria crotonensis Kitton; La barra equivale a $10 \mu \mathrm{m}$. 
da al otro frústulo de la colonia. Pseudorrafe muy estrecha, a menudo indistinta. Frecuentemente se observaron las Dimensiones: 64 x $2 \mu \mathrm{m}$.

Distribución en el mundo: Estados Unidos (Patrick y Reimer, 1966); España y Reino Unido (Novelo, 1998). Esta especie es típica del plancton (Patrick y Reimer, 1966), muy a menudo en aguas mesotróficas o eutróficas y aparentemente no se encuentra en regiones tropicales. Su presencia en el Lago Zempoala podría explicarse porque la temperatura del agua es en general baja y solamente en el verano suele ser de $25^{\circ} \mathrm{C}$. Esto coincide con muchos lagos de latitudes templadas, que alcanzan esa temperatura en el epilimnion durante el verano.

Distribución en México: México, D.F.

Fue la especie dominante del lago y presentó su mayor abundancia en las zonas 2 y 3 , en el mes de junio de 1996. Estuvo presente en las tres zonas. Registrada en toda la columna de agua.

Fragilaria crotonensis Kitton, figura $3 \mathrm{~h}$.

Frústulos gruesos en el centro y atenuadas al final. Los frústulos se unen en la porción media característica de la especie. Valvas linear- lanceoladas; ápice capitado, pseudorrafe indistinta. El área central usualmente rectangular, extendida al margen de las valvas. Dimensiones: $74.5 \times 3.48 \mu \mathrm{m}, 8$ estrías en $10 \mu \mathrm{m}$. Frecuentemente en colonias con 5 células y rara vez observamos células solitarias.

Distribución en el mundo: especie planctónica, muy distribuida en aguas mesotróficas. Estados Unidos (Patrick y Reimer, 1966); Europa, Asia, África y Bolivia, (Novelo, 1998).

Distribución en México: México central, especialmente Hidalgo.

Esta especie presentó su mayor abundancia en la zona 3, en el mes de junio de 1996. Fue registrada en toda la columna de agua del lago, abundante durante todas las recolectas y en las tres zonas.

\section{Synedra ulna Nitzsch.}

Valvas solitarias. Frústulo linear, raramente cóncavo en la mitad, ligeramente atenuados en los ápices que son rostrados. Sin área central. Dimensiones: $72.6 \mathrm{x}$ $2.6 \mu \mathrm{m}, 19$ estrías en $10 \mu \mathrm{m}$.

Distribución en el mundo: España (Aboal y Llimona, 1984); Europa Central (Krammer y Lange-Bertalot, 1991a); Norte América (Sheath y Cole, 1992).

Distribución en México: Puebla.

Esta especie presentó su mayor abundancia en la zona 2, en el mes de mayo de 1996. Poco abundante, registrada en toda la columna de agua, presente sólo en las zonas 2 y 3 de este lago, de manera esporádica.
Orden Naviculales, Familia Naviculaceae.

Gomphonema acuminatum Ehrenberg, figura 3 e.

Valva triondulada, ápice agudo, polo basal recto; rafe ligeramente sinuada, estrías radiales hacia el centro. El área central puede tener una o más estrías más cortas, con un estigma cerca del final de la estría media. Dimensiones: $55 \times 15.2 \mu \mathrm{m}, 9-10$ estrías en $10 \mu \mathrm{m}$.

Distribución en el mundo: Estados Unidos (Patrick y Reimer, 1966); Europa; Irán (Novelo, 1998).

Distribución en México: México central.

Fue una especie esporádica de poca abundancia en las tres zonas y presentó su mayor abundancia en la zona 3, en el mes de junio de 1997. Registrada en este lago en toda la columna de agua.

Gomphonema affine Kützing, figura $3 \mathrm{~d}$.

Valva lanceolada con un ápice obtuso. Área axial bien definida. La estría media corta. Estrías radiadas a lo largo de toda la valva, pero paralelas cerca de la base. Dimensiones: $60 \mathrm{x} 13 \mu \mathrm{m}$; 12 estrías en $10 \mu \mathrm{m}$.

Distribución en el mundo: Estados Unidos (Patrick y Reimer, 1966); Argentina y Europa Central (Novelo, 1998).

Distribución en México: Hidalgo, México central y Puebla.

Fue una especie esporádica, en general poco abundante, presente sólo en las zonas 2 y 3 . Presentó su mayor abundancia en la zona 2, en mayo de 1996. Registrada en este lago en toda la columna de agua.

Frustulia rhomboides (Ehr.) De Toni var. capitata (A. Mayer) Patrick.

Valva linear lanceolada con ápices claramente capitados. Costillas silicosas, estrechas en el centro de la valva, que encierran a una rafe angosta, ensanchada hacia el centro de la valva. Dimensiones: $41.2 \times 11.2$ $\mu \mathrm{m} ; 25$ estrías en $10 \mu \mathrm{m}$.

Distribución en el mundo: Estados Unidos (Patrick y Reimer, 1966).

Distribución en México: no hay registro.

Fue esporádica y poco abundante. Se presentó sólo en la zonas 2 y 3 y su mayor abundancia fue en la zona 2, en el mes de mayo de 1996. Registrada en este lago en toda la columna de agua.

\section{Familia Nitzschiaceae.}

Nitzschia frustulum (Kützing) Grunow in Cleve et Grunow Secc. (Lanceolatae).

Valvas lanceoladas, linear lanceoladas a lineares con ápices ligeramente alargados, agudos, redondeados y ligeramente capitados. En la parte media de la rafe, 
márgenes ligeramente cóncavos; estrías punteadas paralelas, generalmente 2 por fíbula; fibulas cortas irregularmente dispuestas y con un nódulo central evidente. Dimensiones: 22.4 x $4.6 \mu \mathrm{m}, 16$ estrías en $10 \mu \mathrm{m}$.

Distribución en el mundo: cosmopolita (Kramer y Lange Bertalot; Novelo, 1998).

No hay registros en México.

Su presencia fue esporádica y poco abundante en las tres zonas y presentó su mayor abundancia en la zona 2, en el mes de agosto de 1996. Registrada en este lago en toda la columna de agua.

\section{Familia Epithemiaceae}

Epithemia turgida (Ehr.) var: granulata (Ehr.) Brun. figura $3 \mathrm{~g}$.

Valva linear casi recta o moderadamente convexa en el margen dorsal, margen ventral cóncavo. Ápices capitados en el lado dorsal de la valva. La rafe a menudo aparente y en la porción media de la valva está curvada hacia el margen dorsal. Dos o tres hileras de alvéolos entre costillas. La rafe ocupa $3 /{ }_{4}$ partes del ancho de la célula. Presenta 9 hileras de alvéolos en $10 \mu \mathrm{m}, 4$ costillas en $9.5 \mu \mathrm{m}$ y 10 alvéolos en 1 hilera. Sus extremos están capitados. Dimensiones: $570 \times 299 \mu \mathrm{m}$.

Distribución en el mundo: cosmopolita (Patrick y Reimer, 1966; Kramer y Lange-Bertalot 1988).

Distribución en México: Hidalgo.

Fue una especie esporádica de poca abundancia y sólo se presentó en la zonas 1 y 2. Presentó su mayor abundancia en la zona 3, en el mes de junio de 1997. Registrada en este lago en toda la columna de agua.

Orden Achnanthales, Familia Achnanthaceae.

\section{Achnanthes minutissima Kützing.}

Valva linear lanceolada, con los lados ligeramente convexos y los ápices redondeados, subrostrados. La vista conectiva es angular. Las estrías son rectas en

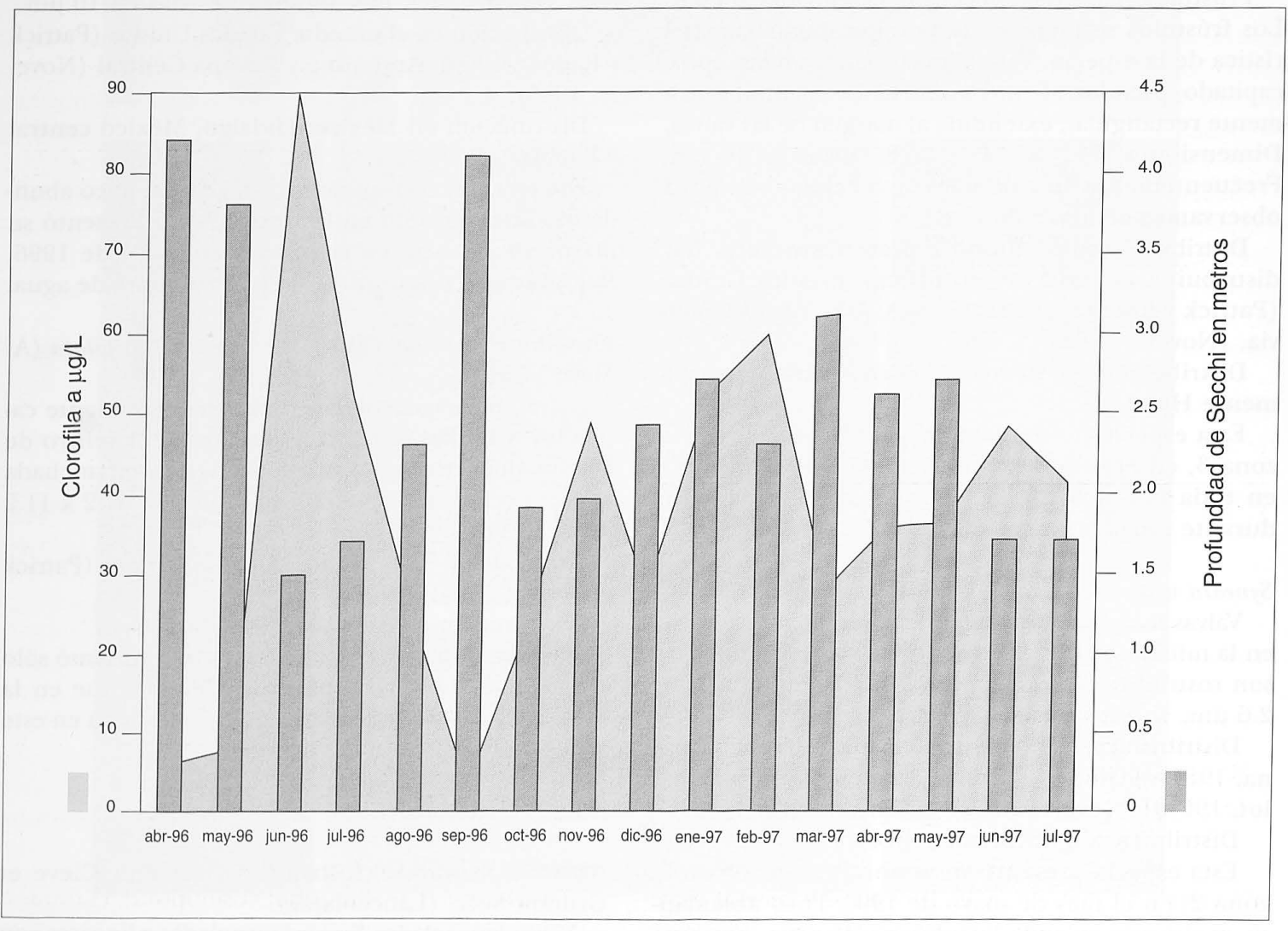

Figura 4. Concentración de clorofila a y transparencia en la zona eufótica del lago Zempoala para el período de estudio, de abril de 1996 a julio de 1997. 
Cuadro 2. Valores de densidad de organismos por litro en la columna, para los períodos de estratificación de verano del lago (1996 y 1997) y de circulación de otoño (1996). Para cada asociación, el valor de densidad de la especie dominante se indica en negrillas.

ZONA 1

\begin{tabular}{|c|c|c|c|c|c|c|c|c|c|}
\hline Profund. & JUNIO 96 & & JULIO 96 & & AGOSTO & & OCTUBRE 96 & JUNIO 97 & JULIO 97 \\
\hline $0-1 \mathrm{~m}$ & $\begin{array}{l}\text { Ast. form. } \\
\text { Tra. stok. }\end{array}$ & $\begin{array}{r}56952 \\
1080 \\
936\end{array}$ & Ast. form. & 16334 & Ast. form. & 6048 & $\begin{array}{l}\text { Ast. form. } 8280 \\
\text { An. cf. port. } 12528\end{array}$ & $\begin{array}{l}\text { Ast. form. } 56160 \\
\text { An. cf. port. } 3384 \\
\text { Anab. } \quad 648\end{array}$ & $\begin{array}{l}\text { Ast. form. } 18432 \\
\text { An. cf. port. } 504 \\
504\end{array}$ \\
\hline $2.5 \mathrm{~m}$ & $\begin{array}{l}\text { Ast. form. } \\
\text { Tra. stok. } \\
\text { Fra. crot. }\end{array}$ & $\begin{array}{r}23760 \\
864 \\
1080\end{array}$ & Ast. form. & 4896 & $\begin{array}{l}\text { Ast. form. } \\
\text { Tra. stok. }\end{array}$ & $\begin{array}{r}1720 \\
432\end{array}$ & $\begin{array}{l}\text { Ast. form. } 11880 \\
\text { An. cf. port. } 4824\end{array}$ & $\begin{array}{l}\text { Ast. form. } \\
\text { Tra. stok. }\end{array}$ & $\begin{array}{l}\text { Ast. form. } 2232 \\
\text { Cos. sub. } 13464\end{array}$ \\
\hline
\end{tabular}

$5 \mathrm{~m}$

Ast. form. 4104

An. cf. port. 4248

ZONA 2

\begin{tabular}{|c|c|c|c|c|c|c|c|c|c|}
\hline Profund. & JUNIO 96 & & JULIO 96 & AGOSTO 9 & & OCTUBRE 96 & JUNIO 97 & & JULIO 97 \\
\hline $0 \cdot 1 \mathrm{~m}$ & $\begin{array}{l}\text { Ast. form. } \\
\text { Tra. stok. } \\
\text { Fra. crot. }\end{array}$ & $\begin{array}{r}50760 \\
1368 \\
936\end{array}$ & Ast. form. 39384 & $\begin{array}{l}\text { Ast. form. } \\
\text { Nitz. frus. }\end{array}$ & $\begin{array}{r}10080 \\
2520\end{array}$ & $\begin{array}{l}\text { Ast. form. } 17784 \\
\text { An. cf. port. } 12204\end{array}$ & $\begin{array}{l}\text { Ast. form. } \\
\text { G. lacus. } \\
\text { O. marss. } \\
\text { Fra. crot. }\end{array}$ & $\begin{array}{r}82152 \\
3384 \\
1070 \\
1008\end{array}$ & $\begin{array}{lr}\text { Ast. form. } & 8424 \\
\text { Fra. crot. } & 648\end{array}$ \\
\hline $2.5 \mathrm{~m}$ & $\begin{array}{l}\text { Ast. form. } \\
\text { Tra. stok. } \\
\text { Tra. hisp. }\end{array}$ & $\begin{array}{r}19512 \\
1152 \\
720\end{array}$ & Ast. form. 11880 & $\begin{array}{l}\text { Ast. form. } \\
\text { Nitz. frus. } \\
\text { Trib. bom. }\end{array}$ & $\begin{array}{r}8136 \\
2232 \\
936\end{array}$ & $\begin{array}{l}\text { Ast. form. } 5112 \\
\text { An. cf. port. } 4896\end{array}$ & $\begin{array}{l}\text { Ast. form. } \\
\text { G. lacus. }\end{array}$ & $\begin{array}{r}16056 \\
504\end{array}$ & Ast. form. 12744 \\
\hline
\end{tabular}

$5 \mathrm{~m}$

Ast. form. 5616

An. cf. port. 4032

ZONA 3

\begin{tabular}{|c|c|c|c|c|c|c|c|c|c|}
\hline Profund. & JUNIO 96 & & JULIO 96 & & AGOSTO 9 & & OCTUBRE 96 & JUNIO 97 & JULIO 97 \\
\hline $0-1 \mathrm{~m}$ & $\begin{array}{l}\text { Ast. form. } \\
\text { Tra. stok. } \\
\text { Fra. crot. }\end{array}$ & $\begin{array}{r}66888 \\
1080 \\
1296\end{array}$ & $\begin{array}{l}\text { Ast. form. } \\
\text { Tra. stok. }\end{array}$ & $\begin{array}{r}26136 \\
648\end{array}$ & $\begin{array}{l}\text { Ast. form. } \\
\text { Tra. stok. } \\
\text { Trib. bom. } \\
\text { Mic. prot. }\end{array}$ & $\begin{array}{r}10224 \\
504 \\
792 \\
1512\end{array}$ & $\begin{array}{l}\text { Ast. form. } 5616 \\
\text { An. cf. port. } 12960\end{array}$ & $\begin{array}{l}\text { Ast. form. } 45144 \\
\text { An. cf. port. } 2160 \\
\text { Gom. acum. } 1080\end{array}$ & $\begin{array}{l}\text { Ast. form. } 14976 \\
\text { Fra. crot. } 1080 \\
\text { An. cf. port. } 576\end{array}$ \\
\hline $2.5 \mathrm{~m}$ & $\begin{array}{l}\text { Ast. form. } \\
\text { Tra. stok. } \\
\text { Fra. crot. }\end{array}$ & $\begin{array}{r}23832 \\
1080 \\
864\end{array}$ & Ast. form. & 9504 & $\begin{array}{l}\text { Ast. form. } \\
\text { Tra. stok. } \\
\text { Tra. hisp. }\end{array}$ & $\begin{array}{r}7056 \\
648 \\
648\end{array}$ & $\begin{array}{lr}\text { Ast. form. } & 9144 \\
\text { Tra. stok. } & 864 \\
\text { An. cf. port. } 5184\end{array}$ & $\begin{array}{lr}\text { Ast. form. } & 19296 \\
\text { Fra. crot. } & 792\end{array}$ & Ast. form. 4824 \\
\hline $5 \mathrm{~m}$ & & & & & & & $\begin{array}{lr}\text { Ast. form. } & 864 \\
\text { An. cf. port. } & 968\end{array}$ & & \\
\hline
\end{tabular}

dirección a la rafe, pero en la valva con rafe, son radiales en el centro, y el área axial y central estrechas. En la valva sin rafe no se presenta herradura intervalvar. Dimensiones: 9.2 × $3.3 \mu \mathrm{m}$. Aunque los frústulos estaban completos, frecuentemente se ob- servaron células sin contenido.

Distribución en el mundo: cosmopolita (Krammer y Lange-Bertalot, 1991b; Novelo, 1998).

Distribución en México: México central y Puebla (Novelo, 1998) 
Fue una especie esporádica y poco abundante en las tres zonas y presentó su mayor abundancia en la zona 2, en el mes de junio de 1996. Registrada en este lago en toda la columna de agua.

Caracterización general del lago. El lago Zempoala es somero con una concentración alta de nutrimentos inorgánicos disueltos, que fueron medidos en algunos meses de $1996\left(\mathrm{NH}_{4}-\mathrm{N}=20 \mu \mathrm{g} \mathrm{l}^{-1}\right.$ en octubre y $580 \mu \mathrm{g} \mathrm{l}^{-1}$ en abril y mayo; $\mathrm{NO}_{3}-\mathrm{N}=600 \mu \mathrm{g} \mathrm{l}^{-1}$ en mayo y $100 \mu \mathrm{g} \mathrm{l}^{-1}$ en julio y $\mathrm{PO}_{4}-\mathrm{P}=60 \mu \mathrm{g} \mathrm{l}^{-1}$ en junio, 650 $\mu \mathrm{g} \mathrm{l}^{-1}$ en septiembre y $230 \mu \mathrm{g} \mathrm{l}^{-1}$ en noviembre) y una biomasa algal considerable ( $54 \mu \mathrm{g} \mathrm{l}^{-1}$ de clorofila $a$ promedio, figura 4). La transparencia parece estar muy relacionada con la densidad del fitoplancton, pues las fluctuaciones anuales corresponden con las modificaciones en las concentraciones de clorofila ( figura 4 , cuadro 2). No hay un desarrollo masivo de cianoficeas y el lago presenta un perfil de oxígeno clinogrado aunque la deplesión no llega a cero en las capas pro-

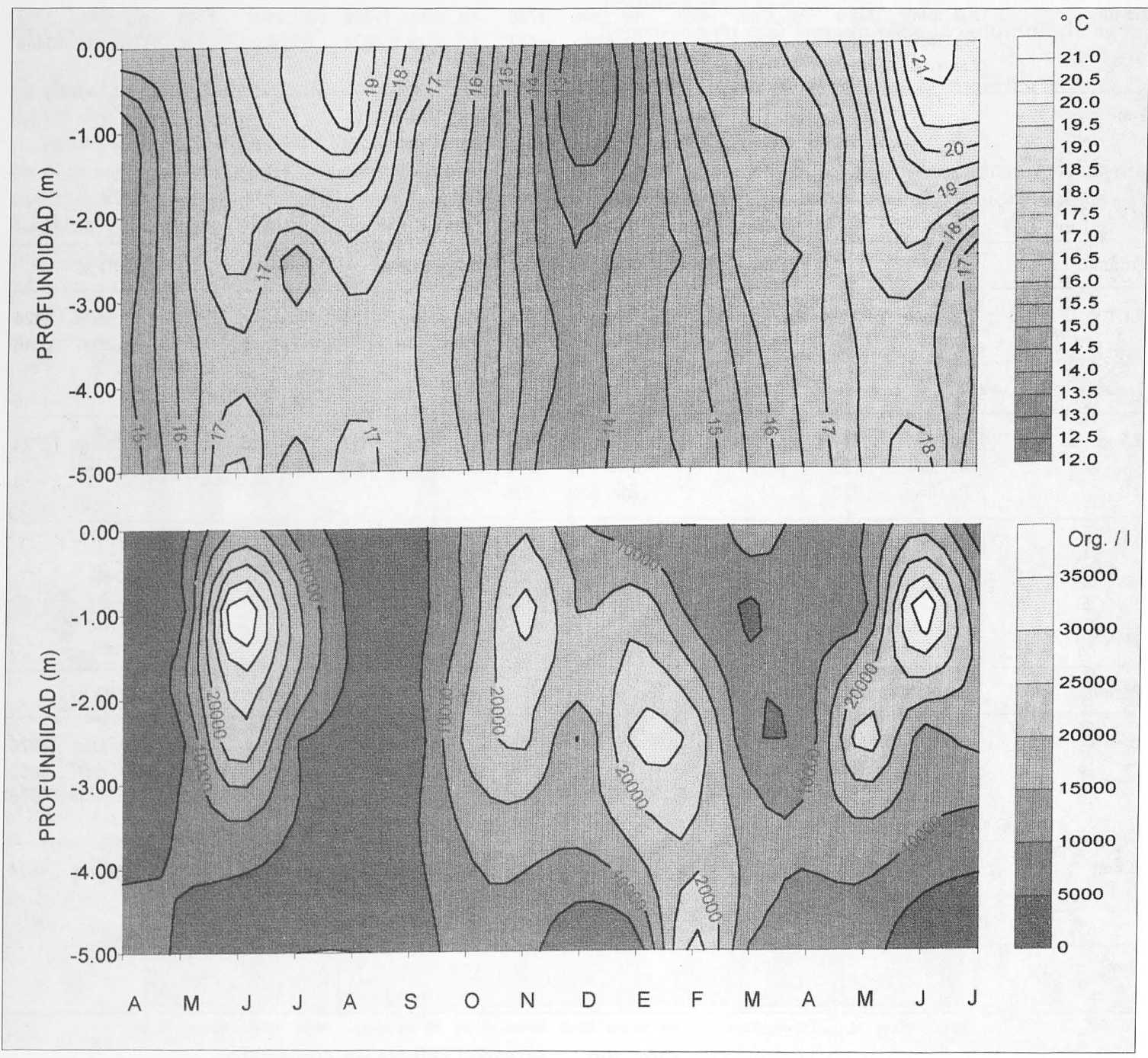

Figura 5. Gráfica superior con isolíneas de temperatura en función de la profundidad total del lago Zempoala. Se muestran los períodos de estratificación de verano e invierno con un termoclín a $2.5 \mathrm{~m}$. Gráfica inferior con isolíneas del promedio de densidades del fitoplancton en la columna de agua del lago Zempoala (org/1). Se muestran parches en la superficie del lago $(0-1 \mathrm{~m})$ durante los periodos de estratificación. 
fundas (García-Rodríguez y Tavera, datos no publ). Atendiendo a los valores promedio, sólo hay el doble de nitrógeno que de fósforo y entonces podemos considerar un valor bajo para la proporción de Redfield (Reynolds, 1984; Wetzel, 1983), de manera que el fitoplancton podría estar limitado por nitrógeno. El fósforo parece ser más escaso en períodos de estratificación y se incrementa durante el período de mezcla del lago.

Caracterización ecológica y geográfica de las especies. La mayoría de las especies presentes en el lago Zempoala han sido registradas sólo en ambientes lénticos y sólo 6 en ambos tipos de ambientes, lóticos y lénticos (cuadro 1). Casi todas las especies han sido registradas alguna vez como planctónicas. La ecología de Staurastrum sebaldii var. ornatum no ha sido documentada con precisión en la literatura, pero en tanto que no tiene registros previos para los trópicos y considerando la presente discusión sobre la "naturaleza" templada del lago Zempoala, (pág. 98), la hemos caracterizado como una especie con distribución templada. Por las mismas razones, también hemos mantenido esta caracterización de distribución templada para Pandorina smithtii, Arthrodesmus convergens, Trachelomonas stokesiana y Frustulia rhomboides var. capitata. Las especies que tienen registros en zonas tropicales, se limitan a localidades cubanas, hindúes y mexicanas. Por otra parte, existe un registro para Anabaena portoricensis de Puerto Rico (Gardner, 1927). La especie presente en Zempoala sin embargo, aunque parece muy cercana a A. portoricensis, carece de acinetos y no podemos certificar su determinación.

Podemos resaltar que más de la tercera parte de las espccies bien reconocidas, presentes en el fitoplancton de este lago, no habían sido registradas anteriormente en México (cuadro 1).

Densidad del fitoplancton y discontinuidades en su distribución en la columna (parches). El análisis de las discontinuidades en la distribución del fitoplancton se hizo a gran escala (con profundidad en metros y con datos obtenidos de recolectas mensuales). En el Cuadro 2 se presentan los resultados en el número de organismos por litro sólo para las especies con una densidad mayor a 400 org / l y para los meses más significativos de los períodos de circulación y estratificación del lago. La gráfica de isolíneas que resume las densidades del fitoplancton (figura 5) hace evidentes las discontinuidades en la distribución espacial; las concentraciones importantes del fitoplancton en la columna (parches), tienden a presentarse en verano (comparar con la gráfica de isolíneas para temperatura en la misma figura), durante los períodos de estratificación del lago. Estas concentraciones en las tres zonas donde se tomaron las muestras, tienen mayor intensidad en la superficie y en los períodos de estratificación de verano e invierno, pero éste último refleja en menor grado la formación de parches en las capas superficiales (figura 5). Aunque la gráfica reune en la escala de menor concentración los valores de 0 a 5000 organismos por litro, los valores para las épocas estratificadas del lago son nulos.

En cuanto a los componentes específicos en las concentraciones mencionadas, Asterionella formosa fue la dominante en la mayoría de los parches (cuadro 2). En la superficie estuvo acompanada por Trachelomonas stokesiana, Fragilaria crotonensis, Nitzschia frustulum, Microcystis protocystis y Tribonema bombycinum en el verano de 1996. En el verano de 1997 los parches de la superficie siguieron dominados por $A$. formosa pero las codominantes fueron Anabaena cf. portoricensis, Gregiochloris lacustris, Fragilaria crotonensis, Gomphonema acuminatum, Oocystis marssonii y Anabaena sp. (cuadro 2).

A 2.5 metros de profundidad Asterionella formosa siguió siendo dominante (excepto en julio de 1997), pero las acompañantes cambiaron. En el verano de 1996 encontramos Trachelomonas stokesiana, Nitzschia frustulum, Tribonema bombycinum y Trachelomonas hispida y en las zonas 1 y 3 se presentó además $F$. crotonensis (cuadro 2).

En junio y julio de 1997 Asterionella formosa fue la dominante y las acompañantes, Trachelomonas stokesiana, Fragilaria crotonensis y Gregiochloris lacustris y en la zona 2; en la zona 1 la dominante fue Cosmarium subtumidum. y la acompañante $A$. formosa. En el mes de julio de los años en que se estudió el lago, $A$. formosa fue la única especie importante en las tres zonas (cuadro 2).

A los 5 metros de profundidad, sólo hubo parches en el período de mezcla de otoño, pero el fitoplancton no formó concentraciones importantes y las discontinuidades en la distribución fueron poco discernibles: parches compuestos por Anabaena cf. portoricensis dominante, o codominante de A. formosa, (cuadro 2).

\section{Discusión y conclusiones}

La composición del fitoplancton del lago Zempoala puede corresponder bien con un lago eutrófico. Las diferencias en las concentraciones de nutrimentos parecen corresponder con los períodos de estratificación y mezcla, de manera que probablemente los nutrimentos de este lago tienen un ciclo estacional anual de sedimentación y suspensión. Si los nutrimentos (principalmente el fósforo, por el tipo de suelo de la cuenca) son remineralizados más rápidamente en las capas superficiales durante el verano, cuando el lago se estratifica, posiblemente están más disponibles en 
el epilimnion para producción primaria. Su rápida utilización podría explicar el incremento en densidad y biomasa (considerada como concentración de clorofila) durante esa época, así como las correspondientes fluctuaciones de transparencia de Secchi (figura 4).

De acuerdo a los resultados obtenidos parece evidente que las épocas de mezcla de la columna posibilitan la erosión de los parches. Asimismo, durante los períodos de estratificación el fitoplancton presenta una distribución claramente diferencial en la columna con una discontinuidad entre epilimnion e hipolimnion (figura 5). Es claro que la especie dominante en el lago, A. formosa, la mayor parte del año supera la densidad del resto de las especies (cuadro 2). Una posible explicación para esta desproporción puede encontrarse en la composición de especies del zooplancton (com. pers. del Biól. R. Trejo), que debido a su talla podría estar controlando preferentemente a las especies pequeñas del fitoplancton, lo que ha sido observado en otros lagos (Queimaliños y Modenutti, 1993)

La caracterización geográfica de las especies que se concluye en las tres últimas columnas del cuadro 1 , indica que hay 5 especies típicamente templadas presentes en el lago Zempoala. Muchas parecen ser comunes tanto en localidades templadas como tropicales, pero la mitad de las especies se marcan con una interrogación porque todavía son poco conocidas en regiones tropicales. A la vez, el componente florístico con distribución tropical en este lago parece ser escaso, posiblemente sólo dos especies, A. portoricensis y Anabaena sp. pudieran tener una distribución limitada.

Podemos concluir que el fitoplancton del lago Zempoala es en general de distribución templada, lo que es consecuente con el tipo de clima que caracteriza el área y la altura en la que se ubica el lago. Es evidente que ambos factores influyen también el tipo de vegetación vascular de la Provincia biogeográfica en la que se ubica el Parque (Ferrusquía-Villafranca, 1990).

La ubicación latitudinal del lago y la cantidad de radiación solar correspondiente (Straskrabá, 1980) deben influir sobre la composición específica del fitoplancton, (Talling, 1957). Pensamos que la composición de especies en el lago Zempoala guarda más similitud con la de lagos de zonas subtropicales y templadas porque el clima predominante es semejante al de dichas zonas.

Cabría preguntarse entonces si las especies como Anabaena cf. portoricensis, Anabaena sp. y Peridinium sp. que hasta ahora tienen un registro preliminar en cuanto a su distribución, tendrían intervalos amplios de tolerancia a factores como temperatura o luz cli- mática, pues sería cuestionable un papel como "elementos tropicales" de un lago que aparentemente presenta una flora común de zonas templadas. Desde luego, esta pregunta no puede resolverse hasta completar, en primer término, la determinación de las especies citadas y en segundo, hasta tener un número mayor de registros para el país y una documentación más precisa de su ecología en áreas tropicales.

Un rasgo general importante del fitoplancton de este lago es la diversidad de grupos presentes (clorofitas, euglenofitas, dinofitas, cianofitas y diatomeas) y es común que en los lagos eutróficos, exista una escasa diversidad de grupos algales, además de que generalmente las cianofíceas llegan a ser el grupo dominante en el fitoplancton (Zevenboom y Mur, 1980; Tavera, 1996). Los datos de nutrimentos obtenidos en este estudio parecen indicar que Zempoala se comporta como un lago eutrófico y es muy posible que su eutrofización esté ocurriendo como un proceso natural, moderado por la sedimentación y recirculación anuales de nutrimentos. Esto es lo que quizá permite una coexistencia balanceada de varios grupos algales (Tavera, 1996).

Finalmente, es necesario puntualizar los criterios que hemos seguido para dar una caracterización del lago Zempoala. Entre otras características, Lampert y Sommer (1994) sugieren considerar la morfometría, relación de volumen epi / hipolimnion, biomasa algal, concentración de nutrimentos después del período de circulación, si hay un desarrollo masivo de cianofitas y el perfil de oxígeno. Zempoala es un lago somero, con una relación de volumen mayor que 1 , con una biomasa algal entre $10-500 \mu \mathrm{g} \mathrm{l}^{-1}$ de clorofila $a$ y con nutrimentos en una concentración > $30 \mu \mathrm{g} \mathrm{l}^{-1}$ después del período de circulación; asimismo, muestra un perfil clinogrado de oxígeno. El florecimiento de cianofitas parece presentarse sólo durante la circulación de otoño, así que este grupo no está desarrollado masivamente, lo que indica que Zempoala comparte 5 de las 6 características mencionadlas. Podemos concluir que es un lago eutrófico y que a pesar de su ubicación latitudinal, la altura a la que se encuentra y las características climáticas derivadas, influyen decisivamente la composición fitoplanctónica, cuya distribución en la columna, densidad y dominancia de especies responde tanto a características físicas, los llamados cambios de tipo alogénico (Lampert y Sommer, 1994), como biológicas, principalmente a la predación del zooplancton, o cambios del fitoplancton de tipo autogénico.

\section{Agradecimientos}

El trabajo de campo fue realizado gracias al apoyo económico de FOMES-SEP que recibió el proyecto de 
Limnología de los lagos del Parque Nacional de Lagunas de Zempoala. Las autoras están en deuda con el Dr. Eberto Novelo del Laboratorio de Ficología, Facultad de Ciencias, UNAM, por la información proporcionada sobre registros de especies de algas de agua dulce de México y revisión del manuscrito. Asimismo, queremos expresar nuestro agradecimiento al Dr. Augusto Comas González del Laboratorio de Investigaciones Algológicas de Cienfuegos, Cuba, por la cuidadosa revisión del manuscrito y certificación de las especies de Clorococales y de la misma manera, a la Dra. Marina Aboal Sanjurjo, de la Universidad de Murcia, España, por sus atinados comentarios y corrección del manuscrito.

\section{Literatura citada}

Aboal M. y Llimona, X. 1984. Aportación al conocimiento de la flora del río Mula, Murcia, SE de España. Limnética 1:141-147

Aceves-Quezada J. 1990. Carta IV.1.1 (A.B.), Atlas Nacional de Mexico, 1990. Instituto de Geografía, UNAM. Vol II Naturaleza.

Apha 1992. Standard Methods for Examination of Water and Wastewater. 17th edition, American Public Health Association. New York.

Bonilla B.J. 1992. Flora y vegetación acuática vascular de las Lagunas de Zempoala, Morelos México. Tesis Maestría Facultad de Ciencias. UNAM.

Comas-González, A. 1996. Las Chlorococales dulciacuicolas de Cuba. Bibliotheca Phycologica. Band 99. J. Cramer Berlin-Stuttgart 192 pp y 65 figuras.

Desikachary T. V. 1959. Cyanophyta. New Delhi. ICAR Monographs on Algae. India Council of Agricultural Research. New Delhi. 686 pp.

Ferrusquía-Villafranca I. 1990. Carta IV.8.10, Atlas Nacional de Mexico, 1990. Instituto de Geografía, UNAM. Vol II Naturaleza.

García E.,1990. Carta IV.4.1 (A) y IV.4.10 (A.B.), Atlas Nacional de Mexico, 1990. Instituto de Geografía, UNAM. Vol II Naturaleza.

Gardner N. L. 1927. New Myxophyceae from Porto Rico. Memoirs of the New York Botanical Garden 7:44 pp.

Geitler L. 1932. Cyanophyceae. En: Rabenhorst's Kryptogamie Flora Akad. Verlageses. Leipzig. 14: 1196 pp.

Hindák F. 1988. Studies on the Chlorococcal Algae (Chlorophyceae). IV Veda Publ. House of Slovak Academy of Sciences, Bratislava. 263 pp.

Hubber-Pestalozzi G. 1955. Euglenophyceen. Das Phytoplankton des Susswassers. Systematiks und Biologie. Die Binnengewasser. Thienemann, A. Vol. 4, Stuttgart. 1135 pp.

Komárek J. y Fott B. 1983. Chlorophyceae (Grünalgen). Ordnung: Chlorococcales. Das Phytoplankton des Süsswaser, Systematik und biologie. Hubber-Pestalozzi, G. Vol. 7 Teil,
I, Band XVI Die Binnengëwasser, Stuttgart, E. Schwizerbart'sche Verlagsbuchhandlung. 1044 pp.

Krammer K. y Lange-Bertalot H. 1988. Bacillariophyceae 2. Bacillariaceae, Ephitemiaceae, Surirellaceae. Band 2/2. Die Süsswasserflora von MittelEuropa. Pascher, A; Ettl, H; Gerloff, J.; Heyning, H.; Mollenhauer, D. (Eds.) Stuttgart. Gustav Fischer Verlag. 596 pp.

Krammer K. y Lange-Bertalot H. 1991a. Bacillariophyceae 3. Centrales, Fragilariaceae, Eunotiaceae. Band 2/3. Die Süsswasserflora von MittelEuropa. Pascher, A.; Ettl, H.; Gerloff, J.; Heyning, H.; Mollenhauer, D. (Eds.). Stuttgart, Gustav Fischer Verlag. 576 pp.

Krammer K. y Lange-Bertalot H. 1991b. Bacillariophyceae 4. Achnantaceae, Kritische Ergänzungen zu Navicula (Lineolatae) und Gomphonema. Gesamtliteraturverzeichnis Teil 1-4. Die Süsswasserflora von MittelEuropa. Pascher A.; Ettl H.; Gerloff J.; Heyning H. y Mollenhauer D. (Eds.) Stuttgart. Gustav Fischer Verlag. 437 pp.

Lampert W. y Sommer, U. 1997. Limnoecology: The Ecology of Lakes and Streams. Oxford Univ. Press. 382 pp.

López-García, J. 1990. Carta IV.7.1, Atlas Nacional de Mexico, 1990. Instituto de Geografía, UNAM. Vol II Naturaleza.

Lorenzen, C. J., 1976. Determination of chlorophyll and pheo-pigments: spectrophotometric equations. Limnology and Oceanography 12: 343 - 346.

Marvan, P., Komárek, J. \& Comas, A. 1984. Weighting scaling of features in numerical evaluation of coccal green algae (genera of the Selenastraceae). Arkive fur Hydrobiologie Supplements 67,4. 363-399 pp.

Miranda F. y E. Hernández, 1973. Los tipos de vegetación de México y su clasificación. Bol. Soc. Bot.Mex. 28:29- 179

Novelo M. E. 1998. Floras ficológicas del Valle de Tehuacán, Puebla. Tesis de Doctorado. Facultad de Ciencias. Universidad Nacional Autónoma de México. 599 pp.

Patrick R. y Reimer, C. W. 1966. The Diatoms of the United States. Vol. 2, Part 1 Monographs of the Academy of Natural Sciences of Philadelphia. 688 pp.

Philipose M. T. 1967. Chlorococcales. Monographs on Algae. Indian Council of Agricultural Research. New Delhi. ICAR. 365 pp.

Popovsky J. y Pfiester A. L. 1990. Dinophyceae (Dinoflagellida). En: Pascher A; Ettl H.; Gerloff J.; Heyning H. y Mollenhauer D. (Eds.) SüBwasserflora von Mittel Europa. Stuttgart. Gustav Fischer Verlag. 270 pp.

Prescott G. W. 1962. Algae of the Western Great Lakes Area. Revised Edition. Dubuque, Iowa. W.M.C. Brown Co. Pub. $977 \mathrm{pp}$.

Prescott G. W., Croasdale H. T., Vinyard W. C. y Bicudo C. E. d. 1981. A Synopsis of Noth American Desmids. Part. II Desmidiaceae: Placodermae. Section 3. Lincoln and London. Univ. of Nebraska Press. 720 pp.

Prescott G. W., Bicudo C. E. y Vinyard W. C. 1982. A synopsis of Noth American Desmids. Part II. Desmidiaceae: Placodermae. Section 4. Lincoln, Univ. of Nebraska Press. 700 pp. 
Queimaliños C.P. y B. E. Modenutti. 1993. Experimental analysis of the rotifer-cladoceran effect on phytoplankton. Internat. Verein. Limnol. 25:943-946.

Reynolds C. S., 1984. The ecology of freshwater phytoplankton. Cambridge Univ. Press. $384 \mathrm{pp}$.

Sheath R. G. y Cole K. M. 1992. Biogeography of stream macroalgae in North America. Journal of Phycology $28(4): 448-460$.

Starmach K. 1985. Chrysophyceae und Haptophyceae. En: Pascher A; Ettl H.; Gerloff J.; Heyning H.; Mollenhauer D. (Eds.) Sübwasserflora von Mittel Europa. Stuttgart. Gustav Fischer Verlag. 515 pp.

Straskrabá M. 1980. The effects of physical variables on freshwater production: analyses based on models. En: Le Cren E.D. y R.H. Lowe-McConnell (eds). The functioning of freshwater ecosystems. International Biological Programme 22. Cambridge University Press. 13-84.
Talling J. F., 1957. Diurnal changes of stratification and photosynthesis in some tropical African waters. Proceedings of the Royal Society B. 147:57-83.

Tavera R. 1996. Phytoplankton of the tropical Lake Catemaco. Ph. D. Thesis. University of South Bohemia, Ceské Budejovice, Czech Republic. 66 pp, 15 Figures; 14 Tables.

Vollenweider R.A. (ed) 1974. A manual on Methods for measuring Primary Production in aquatic environments. IBP Handbook No. 12, Oxford, Blackwell, 225 pp.

Wetzel R.G., 1983. Limnology. Saunders College Publishing. $767 \mathrm{pp}$.

Zevenboom W. y L.R. Mur, 1980. $\mathrm{N}_{2}$-fixing cyanobacteria; why they do not become dominant in Dutch, hypertrophic lakes. En: Barica J. y L.R. Mur (eds) Hypertrophic Ecosystems. SIL Workshop on Hypertrophic Ecosystems. Junk BV Pub. 123 - 130. 